Zhang, Q., Tang, H., Lockee,B. B. \& Jablokow, K.(2020). Exploring Chinese students' learning experience in CIC MOOC 2.0- A study with Chinese online communities. Journal of Educational Technology

Development and Exchange, 13(2), 21-38

\title{
Exploring Chinese students' learning experience in CIC MOOC 2.0- A study with Chinese online communities
}

\author{
Qing Zhang \\ State University of New York at Oswego \\ Hengtao Tang \\ University of South Carolina \\ Barbara B. Lockee \\ Virginia Polytechnic Institute and State University \\ Kathryn Jablokow \\ The Pennsylvania State University
}

\begin{abstract}
This research explores Chinese students' learning experience in the Creativity, Innovation, and Change (CIC) Massive Open Online Course (MOOC) 2.0 from the cultural, language, and communication perspectives. The CIC MOOC was the first course offered in both English and Chinese in Coursera. Data in this study were collected via online survey, interviews, $Q Q$ chat logs, and discussion threads in Guokr platform. Content analysis was performed to identify key themes from the collected data. Findings reveal that differences exist in Eastern and Western societies regarding power distance, individualism versus collectivism, and masculinity versus femininity. Communication patterns also vary in $Q Q$ and Guokr online communities. In addition, Chinese students reported that translation helped them understand the course topics better, and the online interest group motivated them to participate in course activities and complete the course. The conclusions shed light on the design of future MOOCs, advocating for translating course content into different languages and building small online communities to meet learners' needs and improve their learning experiences.
\end{abstract}

Keywords: MOOC, translation, QQ, Guokr, Cultural differences

Volume 13, No. 2, December, 2020 


\section{Introduction}

E-learning is growing fast with its unique features of openness, easy accessibility and affordability (Allen \& Seaman, 2018; Johnson, Bates, Donovan, \& Seaman, 2019). Learners can access online learning materials regardless of time and location. Massive Open Online Course (MOOC) is an innovation in distance education (Siemens, 2013; Tang \& Carr-Chellman, 2016). Many MOOCs are offered by prestigious universities to global audiences for free (Xing et al., 2019; Zhang et al., 2016). According to Guokr annual MOOC report (2014), most Chinese MOOC learners were below the age of 30 (12-30) from large cities and major school districts with advanced education systems. They also found that Chinese learners enjoyed learning from multimedia materials, such as short instructional videos (Tang \& Wang, 2019). However, a majority of MOOCs are created in English (Kizilcec, Saltarelli, Reich, \& Cohen, 2017; Sanchez-Gordon \& Luján-Mora, 2014), and language barriers inhibit non-native English speakers from fully engaging in those courses (Chopra \& Syazwani, 2020; Lin, Lee, \& Chen, 2004; Liu, 2017; Sanchez-Gordon \& Luján-Mora, 2014).

Low English proficiency not only slows down non-native English speakers' reading speed (Sanchez-Gordon \& Luján-Mora, 2014), but also amplifies cultural issues in online courses (Ku \& Lohr, 2003; Liu, Liu, Lee, \& Magjuka, 2010; Tang, in press). The translation of MOOC content could remove the language barriers and reach a broader global audience with promoting cross-cultural learning (Ding et al., 2014). Although translating the course content into different languages could increase MOOC accessibility, Colas, Sloep, and Garreta-Domingo (2016) pointed out that translation is not enough to eliminate cultural issues. De Waard et al. (2014) and Welsh and
Dragusin (2013) also reported that MOOC learners face the challenge of understanding different cultures. International students have experienced marginalization and difficulty in interacting with others in online courses (Chen \& Oakley, 2020; Liu et al., 2010), including MOOCs. Research has indicated that students from non-English speaking countries maintained low visibility and participation in MOOC discussion forums (Cho \& Byun, 2017; Tahirsylaj, Mann, \& Matson, 2018).

Forming online learning communities based on learners' preferences, such as language, has been utilized to mitigate cultural issues (Colas et al., 2016; Zhang et al., 2016). An online community consists of learners who share the same interests or concerns and interact in an online environment (Phang, Kankanhalli, \& Sabherwal, 2009). Social media platforms, such as blogs and Facebook, are used as learning spaces by various online communities, including non-English speaking groups (Mackness, Mak, \& Williams, 2010). Learners participate in online communities to share and construct knowledge (Gannon-Leary \& Fontainha, 2007; Phang et al., 2009; Tang et al., 2018). By interacting with other group members, learners could develop skills and solve problems quickly (Wenger \& Snyder, 2000).

Although research has been done to investigate Chinese students' learning experiences in credit-bearing online courses (Dennen \& Bong, 2018; Lin, Deng, Hu, \& Tsai, 2019; Ma, 2017; Stork, Zhang, \& Wang, 2018; Thompson \& Ku, 2005; Zhao \& McDougall, 2008), few studies examined Chinese students' experiences in a MOOC. $\mathrm{CIC}$ MOOC is the first MOOC being translated entirely into Chinese. As such, this study investigated how translation might have helped Chinese learners complete the course, explored various tools that were used by students in their learning process, and 
examined what happened inside the Chinese online learning communities, such as in QQ and Guokr MOOC forums. QQ is one of the most popular social media and instant messaging tools in China, and Guokr is a Chinese MOOC discussion forum hosted by a science and technology company (https:// mooc.guokr.com/).

This study aimed to investigate Chinese students' learning experiences in the CIC MOOC 2.0 from the language and cultural perspectives. The CIC MOOC introduced different approaches to stimulate creativity, innovation, and change. One fourth of the course participants were from China, partly because creativity education has been prioritized in K-12 schools, and creativity has been highly valued by the Chinese society (Hui \& Lau, 2010; Wu \& Albanese, 2010). By conducting interviews with Chinese MOOC learners and analyzing conversation logs in two Chinese social media platforms, QQ and Guokr, this study examined how participating in self-formed course-related online learning communities assisted Chinese students' learning processes in the CIC MOOC. The findings shed light on the design of MOOCs with integrating various features to meet the needs of learners coming from various backgrounds. The findings also provided suggestions for MOOC instructors and designers regarding translating the content into multiple languages and adopting external learning environments to assist non-native English speakers in the course.

Specifically, the research questions are as follows.

- What were Chinese learners' experiences in taking the CIC MOOC in consideration of language barriers, cultural differences, and the impact of Chinese translation on their learning?
- How did they form and perform in the online QQ study group, and to what extent did this group help them progress in this course?

- What were the interaction patterns in the QQ and Guokr online communities?

\section{Conceptual Framework}

The conceptual framework for this study includes Hofstede's (2011) cultural dimensions and the works on online learning communities (Garrison, Anderson, \& Archer, 2000). This study sought to understand Chinese students' learning experiences and cultural barriers in the lens of Hofstede's (2011) works on cultural dimensions and then build a preliminary understanding of how self-formed online learning communities may benefit Chinese learners in MOOCs.

\subsection{Dimensions of Cultural Differences}

Hofstede (2011) proposed the 6-dimensions of cultural differences framework, which includes "Power Distance" (PD), "Uncertainty Avoidance" (UA), "Individualism versus Collectivism" (IC), "Masculinity versus Femininity" (MF), "LongTerm versus Short-Term Orientation (LTO)", and "Indulgence versus Restraint (IR)". PD refers to the obedience of supervisors and authorities within a society, UA represents members' attitudes and abilities to handle unpredicted future, IC reflects the extent to which members in a society act as individuals or in groups, MF refers to the strong desire for power and success within a society, LTO reflects the characters of a society on setting the long-term and short-term goals, and IR differentiates whether a society focuses mainly on social norms or personal entertainment.

Christensen et al. (2013) found that an 
increasing number of learners from developing countries (e.g., China and India) were enrolling in MOOCs. Hofstede's (2011) model of cultural dimensions provides a new lens to understand how culture influences learning in MOOCs. For example, Tang and Wang (2017) argued that people from a culture with a high PD value were less likely to register for MOOCs when the variable of Internet access was controlled for analysis. In addition, culture may shape students' patterns about certain important learning skills, such as selfregulated learning (Tang, in press), and further influence student learning performance and persistence in MOOCs.

According to Hofstede (1986), China was dominated by a masculine culture, and success was measured by material success and power. Hofstede (1983) also stated that Asian people maintain a high-power distance within their social systems and sought protection and solution from authorities. Oyserman, Coon, and Kemmelmeier (2002) found that Americans scored higher in individualism and lower in collectivism, while Chinese scored lower in individualism and higher in collectivism. However, a study revealed that with the increasing economic affluence in Asian countries, the gap between Asian collectivism and Western individualism would be reduced (Hofstede, 2007). Hofstede (2007) also argued that power distance indicates the attitudes towards authority in an organization, which was a reflection of the relationship between parent and child in Chinese society. Different from the Confucian approach instilled in the eastern education system that emphasizes knowledge acquisition rather than creation, western education was based on the Socratic approach where learners challenged the authorities and tended to solve problems on their own (Sadykova, 2013).

\subsection{Online Learning Communities}

Various types of online learning communities have been formed to share knowledge and resources and fulfill learning goals (Schwier, 2007; Swan \& Shea, 2005). Social presence is identified as a key factor that impacts learning outcome in an online medium, and it is also defined as the ability of participants to express themselves both socially and emotionally (Garrison et al., 2000; Anderson, 2004). Swan and Shea (2005) stated that social presence was created via communication and interaction between group members in an online environment. In addition, Huett et al. (2007) pointed out that online groups provided learners with community support and helped release their anxieties in using technologies.

Social media tools have been used to form online communities and provide virtual spaces for learners to interact with their peers and instructors (Kapoor et al., 2018; Kimmerle, Moskaliuk, Oeberst, \& Cress, 2015; Yang, Quadir, Chen, \& Miao, 2016). Some of the most often used tools are Facebook, wikis, blogs, and online forums. Many instructors have integrated these tools into their curriculum to increase learner participation, provide social support, and improve learner performance (Chugh \& Ruhi, 2018; Peeters, 2019; Yang et al., 2016). QQ and WeChat are social software used by Chinese students and instructors for online learning (Li, 2012; Zeng, Deng, Wang, \& Liu, 2016; Zhang \& Xue, 2015). During the COVID-19 pandemic when a large of number of classes were moved online, QQ and Webchat were used extensively to facilitate online education in China (Chen et al., 2020; Zhu \& Liu, 2020).

\section{Methodology}

\subsection{Sampling Strategies}


This research adopted a case study method to explore Chinese learners' experiences in the CIC MOOC 2.0. Case study aims to describe and understand human activities in the real world (Creswell, 2013; Gillham, 2000). The unit of analysis can be an individual, group, office, or institution (Tellis, 1997a, 1997b). Indepth analysis of the case is achieved through data triangulation, and the sources of evidence include interviews, observations, and archived materials (Creswell, 2013; Tellis, 1997a). To produce reliable findings, data were collected from multiple sources, including surveys, interviews, QQ chat logs, and Guokr discussion threads.

A call for participation survey was sent out to the QQ group that contained 256 members, and six of them responded and agreed to participate in interview. Two of them were middle and high school students, two were college students, and the rest were working adults. Additionally, two instructors from the CIC MOOC were recruited to interview with the research team.

\subsection{Data Collection}

Virtual interviews were conducted with those six students in Chinese, and face-toface interviews were conducted with two MOOC instructors in English. The two faceto-face interviews with the course instructors were audio taped and transcribed, and notes were taken during the virtual interviews with student participants. Other materials included 900 pages of QQ chat log records, Guokr Discussion forum posts (in Chinese), and course artifacts (e.g., course exercises).

\subsection{Data Analysis}

Firstly, the Chinese interview notes, chat $\log$ records, and discussion threads were transcribed line by line to identify certain codes and themes. All of the emerging themes and codes were translated into English afterwards. The interview scripts were analyzed and transcribed based on Hofstede's six dimensions of cultural differences (see Figure 1).

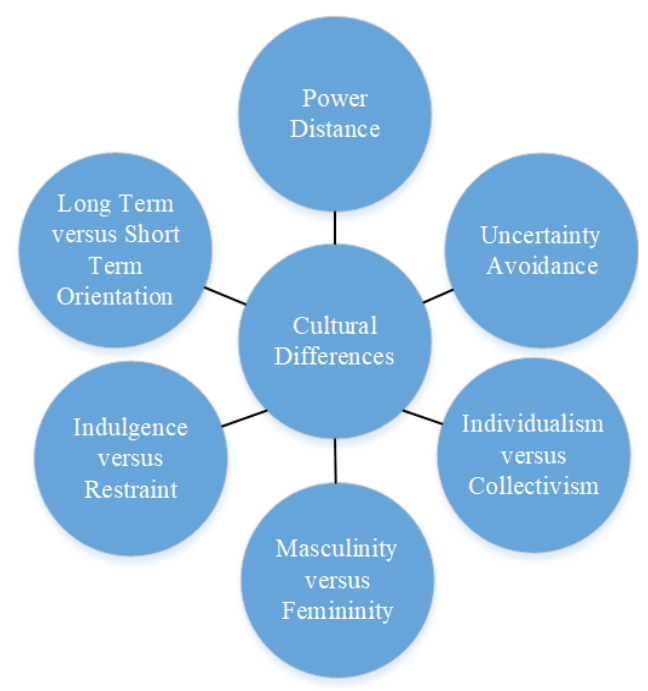

Figure 1. Hofstede's 6-dimension of cultural differences

The chat logs were analyzed using Henri (1992) and Hara, Bonk, and Angeli (2000)'s work to perform content analysis in different social media platforms, including QQ (see Figure 2 of the QQ group discussion interface) and Guokr (see Figure 3 of the Guokr discussion forum).

The coding construct for this study, as seen in Table 1, was built upon Henri (1992) and Hara et al.'s (2000) work related to content analysis in online discussions. Four categories were included in this coding construct: social, cognitive, metacognitive, and maintenance. Social is defined as noncontent related talk when students introduced themselves and greeted each other or had conversations that were not related to the course content. Cognitive contains four sub- 


\section{有创业内容}

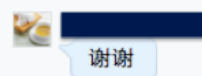

$\operatorname{Jan} 10 \quad 04: 2$

谢谢

\section{$-\infty$}

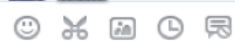

Figure 2. QQ interaction interface

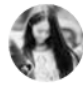

挺好玩的, 在课程中得到了很多启发, 后面的课程很走心, 创新这个还是要看自己, 最重要的就是把学到的应用到实践中。

晒证书

CERTIFICATE

(2)

2015-06-10 19:26

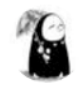

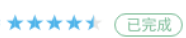

鞋塔估计是全部作业中 最能激发创意的了。

本课程将创意，讲变革，更鼓励和教授你如何把自己的创意应用到生活之中。

因此我觉得有创业欲望的同学可能更对胃口。

晒证书

CERTIFICATE

2

2015-05-07 11:41

Figure 3. Guokr discussion forum posts 
categories, including sharing course content related information, posting a question, and replying to each other's posts, and drawing conclusions. Metacognitive includes posts on students' reflections of their thinking processes. Maintenance consists of posts that are related to course management, such as issues related to where to submit an assignment, the deadline for assignments, how to get a certificate, etc.

Table 1. Modified content analysis framework in online discussion by Henri (1992) and Hara, Bonk, and Angeli (2000)

\begin{tabular}{|l|l|l|}
\hline Levels & Categories & Description \\
\hline Social & $\begin{array}{l}\text { Non-content related } \\
\text { conversation }\end{array}$ & $\begin{array}{l}\text { Self-introduction, greetings, discussion or posts that } \\
\text { are not related to the course topics itself }\end{array}$ \\
\cline { 2 - 3 } & Sharing & $\begin{array}{l}\text { Share information or ask a question related to the } \\
\text { course topics }\end{array}$ \\
\cline { 2 - 3 } & Inference & $\begin{array}{l}\text { Describe a previous asked question, shared } \\
\text { information or statement using one's own words, and } \\
\text { ask for clarification on one's understanding of others' } \\
\text { posts }\end{array}$ \\
\cline { 2 - 3 } & $\begin{array}{l}\text { Come to a conclusion/conclusions with sufficient } \\
\text { evidence and rationale by referencing to internal or } \\
\text { external resources, or connecting to one's own/peers' } \\
\text { previous posts, and etc. }\end{array}$ \\
\cline { 2 - 3 } & Application of Strategies & $\begin{array}{l}\text { Apply the strategies concluded or learned in the } \\
\text { course or during discussion in real world contexts }\end{array}$ \\
\hline Metacongnitive & $\begin{array}{l}\text { Self-regulation \& } \\
\text { Awareness }\end{array}$ & $\begin{array}{l}\text { Reflect on the overall process on completing the tasks } \\
\text { Technical support }\end{array}$ \\
\hline Maintenance & $\begin{array}{l}\text { Seek help on resolving technical issue, e.g. } \\
\text { about assignment due date, and etc. }\end{array}$ \\
\hline
\end{tabular}

\section{Findings}

The Chinese students' learning experiences were explored from three aspects, which were the effects of the translation of the CIC MOOC content to Chinese, the attributes of online Chinese community based on Hofstede's six-dimension model of national culture (Hofstede Insights, n.d.), and the communication patterns found within the two Chinese social media platforms used as a part of the CIC MOOC.

\subsection{The Effect of Translation}

To accommodate the language needs of
Chinese students, all of the course content was translated into Chinese, and Chinese subtitles were added to the videos. The translation was conducted by two native Chinese speakers who attended graduate school in the U.S. with high English and Chinese proficiencies. Each translation was reviewed by both translators to increase its accuracy.

When asked about the intentions of translating the course into Chinese, one instructor replied:

A year ago, I attended the Coursera partnered conference in London, and at that time, they said that they decided to change 
the technology so that Chinese can take the course. Prior to that, YouTube plays the course videos, and YouTube is not accessible in China. Chinese student couldn't take it. But they (Coursera) had made arrangements to use Chinese websites. And so I came back with an idea in my mind, we were working on the second version of CIC MOOC. The course was to be offered starting in July 2013, and sitting there with one of my collaborators, and we had really finished the English version of the course, yet we got a couple of weeks, and I got the idea of why don't we see if we can do a Chinese version.

However, all the course assignments and exercises were still required to be completed in English. Most of the interviewees in this study possessed low to medium English proficiency. When they were asked how the translation affected their experience in this course, one interviewee said: "I read the translated scripts when I couldn't understand the English dialogs." It revealed that translation helped students understand the course content better with their limited English vocabulary.

Husain's (1995) research showed that the translation to Chinese benefited learners with low English proficiency more than it did for learners with high English proficiency. L2 (second language) learners used translations to compare and associate the meaning of the word between English and Chinese. When asked about what type of tools they used to complete the assignments, their replies were quite similar; the Chinese-English dictionary was the most popular tool they used to look up new words. Some reported receiving help from their English teachers or peers with advanced English skills.

\subsection{Cultural and Language Dimensions}

\subsubsection{Moving out of Coursera discussion forum}

In comparison with a large number of Chinese enrollments in the CIC MOOC, much less Chinese students participated in the Coursera discussion forum. Based on the interviews with a sample of the Chinese learners, insufficient English proficiency, cultural differences, and too many discussion sections all inhibited Chinese learners from fully participating in the Coursera discussion forum.

Three interviewees posted in the Coursera discussion forum at the beginning of the course, while the rest never used it. The participants also reported that their posts were ignored by others, and the English posts were too hard for them to understand and took too much time to read. As one participant said: "I logged in once, but the English conversations were too difficult for me to understand. It would be better if there were separate sessions for Chinese discussion."

\subsubsection{Adopting $Q Q$ for group discussion}

As non-native English speakers, Chinese students found it hard to understand the English posts in the Coursera discussion forum. In addition to the language barrier, the cultural difference adds another layer of difficulty for Chinese learners to comprehend the English sentences in certain contexts. Without being exposed to another culture previously, it is hard to understand the context of the dialogues and actions taking place in that culture (Oberg, 1960). Wen, a junior in high school, replied:

I don't have enough time to participate in the Coursera Discussion Forum. Firstly, it was troublesome for me to log into Coursera, and I encountered some bandwidth and Internet connection issues when I logged into Coursera from China. However, I can do instant messaging when I logged into QQ. English is not my mother tongue. I need to 
sit down and study the English context in order to participate in the discussion or write in English, and it also took me a while to comprehend other people's posts. In contrast, in my daily life, I was very often in a noisy environment where I couldn't focus on writing paragraph after paragraph in English. Using QQ, we all talk and type in Chinese, I can still spare one or two minutes to read and reply to the messages even when I was hanging out with friends.

Although Coursera provided asynchronous (not in real time) discussion forums that allowed learners more time to create and comment on each other's posts, it still took Chinese learners a significant amount of time to respond in English. The feeling of ignorance and being lost in the forum and the difficulties encountered in understanding English posts pushed Chinese learners to move out of the Coursera discussion forum and form their own online QQ discussion group. Within the QQ group, it was much easier for them to type in Chinese and receive instant feedback from their peers.

\subsubsection{Collectivism}

According to Hofstede $(1986,2007)$, China ranked high in collectivism. Members in the QQ group and Guokr discussion forum shared resources and supported each other to proceed in this course. Participants also expressed that they gained new knowledge and enjoyed the group diversity. As a QQ group member Wen said: "I enjoyed the QQ group discussion. People in the group come from different places with various occupations. I learned new stuff by just chatting with them. Our conversations varied from course related topics to life, study and work."

According to the interview with the QQ group administrator, a sophomore in College, she reported that she was hired by Guokr a year ago to manage the Guokr discussion forum as well as to promote this course through various social media platforms. The QQ group was initially created by her to promote this course among QQ users. Other behaviors identified from the QQ group included seeking help and taking care of one another, which are all key features of a collectivism community. Members in this QQ group held one another accountable and provided support for their group members. Meanwhile, Chinese participants also viewed participation in this QQ group as an opportunity to socialize and make friends.

\subsubsection{Long-term orientation and masculinity}

According to Hofstede and Minkov's (2010) survey of 23 countries, China scored the highest in long-term orientation. The long-term orientation highly correlated with economic growth and was added as the fifth dimension of cultural differences (Hofstede $\&$ Minkov, 2010), a factor used to explain the fast economic growth in China.

According to the survey report from Guokr (2014), the top three motivations of Chinese students for enrolling in MOOCs were to gain new knowledge, acquire skills needed at work, and improve English proficiency and prepare to study abroad. Learning from other countries is defined as a key feature of a long-term-oriented society (Hofstede, 2011). Chinese students were curious about Western education, and they were not satisfied with what they had been taught in school with lecture-based instructions. MOOCs opened the door to top-notch western education and satisfied the curiosity and learning needs of Chinese students. Di, a freshman in a Chinese college, mentioned: "By taking this course, I would like to see how the creativity course is designed and delivered at an American university." Learning from developed countries and aiming to achieve higher goals, 
such as improving English proficiency and preparing to study abroad, revealed the longterm orientation of Chinese learners.

Hofstede (1986) defined a masculine society with key features of success-driven and wealth-oriented social values. During the interviews, Chinese students complained about the burden of heavy coursework loads, severe competition they were facing in the job market, and familial and societal pressures. The fear of an uncertain future and competitive environment forced students to learn as much as they could to survive in school and work. The Chinese education system is examoriented, which requires students to pass numerous exams from $\mathrm{K}-12$, even to college level. The most important exam was called "Gaokao" in Chinese, which was the Chinese College Entrance Exam. Each student gets one chance per year to take the exam and would be accepted to college once they pass the exam. The higher score they received; the higher chance they would get admitted to top universities. Many Chinese believed their fate was determined by this exam, as one participant said: "I think a college degree from a good school means a brighter future."

\subsubsection{Power distance}

China has a teacher-centered and examoriented education system (Wang \& Farmer, 2008). Teachers lectured throughout the whole course, and students were busy taking notes and memorizing the facts to pass exams. In contrast, there was less power distance between teachers and students in western education systems (Hofstede, 1986), and the course delivery methods were also more diverse and flexible. In a Western classroom, students could interrupt the teacher and hold different opinions from the teacher's. The power distance was fairly high for China compared with this of western countries
(Hofstede, 1986). Chinese students enrolled in this MOOC also hoped to receive feedback from the instructors instead of from their peers, and they believed that the teacher's feedback would be more constructive and valuable. As Lei, a middle school student said:

I don't like the feedback received from the peers, and I prefer to receive feedback from the instructor. Because Chinese teachers normally graded each question and highlighted the errors and wrote down the solutions. While for the peer review in this course, the answers or feedback I received may not be accurate or helpful. I hope to receive the correct answer and improve my understanding of course topics.

Chinese students believed in authority and their teachers without questioning, which again indicated the high-power distance in China.

\subsection{QQ Chat Log and Guokr Discussion Analysis}

The chat $\log$ and Chinese forum discussions were analyzed based on modified Henri (1992) and Hara et al. (2000)'s computer conferencing content analysis framework. The top three levels/types of talk in QQ were social cue (non-content related discussion), sharing, and maintenance. In contrast, the top three levels/types of discussion that took place in Guokr were sharing, clarification, and application of strategies, which are part of cognitive thinking process. Both groups had a higher percentage of sharing, where learners shared content related information, posted questions or made a claim. For the QQ group, 30.2\% of the discussions were course maintenance related discussions, including how to apply for the certificate of accomplishment, how to navigate through the submission system, or what steps were involved with peer assessment. However, 
$22.4 \%$ of discussions in QQ were not related to the course topics at all. For the Guokr discussion, more high-level, sophisticated cognitive thinking processes were revealed from their discussions, including inference $(9.8 \%)$ and application of strategies $(16.3 \%)$.
Participants in Guokr managed to make conclusions with sufficient evidence and logical reasoning; furthermore, students elaborated on the application of knowledge acquired from this course into real-world scenarios.

Table 2. Comparison of types and levels of talks in QQ and Guokr

\begin{tabular}{|c|c|c|c|}
\hline Levels & Categories & $\begin{array}{l}\text { QQ Discussion } \\
(\%)\end{array}$ & $\begin{array}{l}\text { Guokr Discussion } \\
(\%)\end{array}$ \\
\hline Social & Non-content related conversation & $22.4 \%$ & $3.3 \%$ \\
\hline \multirow[t]{4}{*}{ Cognitive } & Sharing & $28.4 \%$ & $45.9 \%$ \\
\hline & Clarification & $8.7 \%$ & $13.2 \%$ \\
\hline & Inference & $3.4 \%$ & $9.8 \%$ \\
\hline & Application of Strategies & $6.9 \%$ & $16.3 \%$ \\
\hline Metacognitive & Self-regulation \& Awareness & $0 \%$ & $9.8 \%$ \\
\hline Maintenance & Technical support & $30.2 \%$ & $1.7 \%$ \\
\hline
\end{tabular}

The Guokr discussion forum was an asynchronous platform open to the public. In the forum, more sophisticated and serious discussions were observed. Since Guokr discussions could be viewed by the public, participants were more aware and careful about the threads they posted. Inappropriate posts were also removed by the administrator when it came to netiquette concerns. In contrast, QQ was a private online discussion group; only group members could view their discussions. The conversations in QQ tended to be more casual. Since QQ was invented as an instant messaging tool, group members did not spend much time to refine or correct their spelling and wording before sending their messages to the group.

The differences between public and private discussion forums may imply adopting different social media platforms in MOOCs for group interaction based on technology affordances and various learning goals. Giving students the freedom to choose their preferred social media platforms and form their own study groups could facilitate their course completion.

\section{Discussion}

The findings of this study suggest that the translation of the MOOC content into Chinese helped Chinese students understand the topics and saved them a lot of time. Within the QQ group, students supported each other and built social connections. Interviews with Chinese students revealed that Chinese society possessed the features of high power distance, collectivism and masculinity. Hofstede (1983, 1986) viewed this higher power distance between Chinese teachers and students as a replication of parent-child relationship in family, boss-employee relationship in an organization, and authority-subordinate in a community/society. The beliefs in authorities explained the request from students in this MOOC to receive feedback from the instructors instead of from their peers. Dorner and Gorman (2006) stated that in a collectivist society, people believed the young should 
learn and receive education, which was the social value deeply imbedded in Chinese culture. Most of the participants were middle and high school students who were was trying to learn as much as they could either inside or outside school. Many of them viewed taking this MOOC as an opportunity to learn during summer break. Another feature of Chinese society is masculinity, which was reflected from the goals set by those participants to become competent and successful in their current and future careers.

Hofstede (2007) stated that "a relationship exists between economic affluence and cultural individualism" (p. 417), which meant that people from rich countries tended to be or become individualistic. He used an example in wealthy Asian countries, such as Japan and South Korea, where older people were less taken care of by their offspring than before, as evidence to show that their cultures were shifting from collectivism to individualism. However, other factors may explain this shift; the economic growth and globalization in these countries has prompted the younger generation to seek opportunities in big cities or abroad, necessitating less time and ability to look after their parents.

\subsection{Limitations}

Not all the cultural factors in Hofstede's (2011) model were accurately described or fit the current phenomena across various societies around the world. China scored high on Restrained; however, it did not have all of the primary features of a restrained society. For instance, a restrained society is described as wealthy countries and larger police force, which is not the case in all regions across China. Jones (2007) believed that Hofstede was trying to define a society as a whole while ignoring the variances among the subgroups within a society or country. Based on the facts that this study was conducted in a global corporation - IBM, the survey results may not represent the circumstances in the entire society. Even though this study nicely represents the cultural differences among Eastern and Western societies, it mainly focuses on identifying the cultural differences across the countries in the business world. Another limitation in Hofstede's model was the sample size; some of the sample sizes were quite small and not representative. For instance, they only took samples from 23 countries to study the long-term orientation and short-term orientation. As China is growing fast, and the society has been heavily influenced and shaped by other cultures, there is no simple definition or description of the cultural dimensions in modern Chinese society.

Also, the findings from this study were not generalizable. Firstly, the sample size is small given the size of the QQ community; only six out of 256 people in the online group volunteered to take the interview. Secondly, the interviewees for this study were from the younger Chinese generation, and they were born in an age of globalization with more exposure to Western cultures. They have generally become accustomed to accepting changes and learning new skills. In contrast, members from the older generation were rarely taught English in school and had less interest or ability to explore the outside world. This generational difference could impact the outcome of the study if participants were recruited from the old generation. Thirdly, English proficiency may have also caused differences in the findings. Since most of the participants were with low to medium English proficiencies, the answers for interview questions would likely to be different for learners with high or advanced English proficiencies. 


\section{Conclusion}

The formation and interaction within the QQ group demonstrated that collectivism is highly valued by Chinese culture. Chinese people chose to work in groups, especially with whom they share common goals, language, and culture. Learning communities, for instance this QQ group, were necessary to support knowledge discourse, information sharing, and sense making during the learning process. Therefore, this research on the formation of a self-organized Chinese online learning community could bring insights into the redesign and innovation of future MOOCs, while providing and maximizing peer support for the non-native English speakers. As many MOOCs were delivered in English and under Western education context, it was challenging and intimidating for non-native English speakers to adapt to the language and cultural shifts. As Liu et al. (2010) claimed, designers should be aware of cultural diversity when designing a cross-cultural course, such as a MOOC. To satisfy the needs of all learners and create a more welcoming environment for the global audience, it might be helpful to integrate the cultural elements from a number of countries into the MOOC design process.

Since their inception, MOOCs have benefitted people who do not have easy access to higher education (Christensen et al., 2013; Lambert, 2020). For example. MOOCs have been popular in developing countries such as China and India. Bischoff (2014) reported that more Chinese people were taking MOOCs on mobile devices, saying: "Coursera's mobile app will be on the frontier of its expansion into Asia, especially for less affluent people. A mobile app that allows these people to predownload lessons can spread quality education to all economic classes." MOOCs have the potential to serve as a catalyst to redistribute education resources worldwide. In the era of
MOOCs, small groups can be formed in each course to offer peer assistance and promote learning (Krasny et al., 2018). Social media could play an import role in facilitating group work, fostering peer learning, and generating multilingual and community-based learning experiences (Colas et al., 2016; Li, Wang, \& Tan, 2018). 


\section{References}

Anderson, T. (2004). Social software to support distance education learners. Theory and practice of online learning (pp. 221-241). AU Press.

Bischoff, P. (2014, May 6). Coursera picks up steam in China as more students take MOOCs on mobile. https://www. techinasia.com/coursera-picks-steamchina-students-moocs-mobile/

Chen, K. Z., \& Oakley, B. (2020). Redeveloping a global MOOC to be more locally relevant: design-based research. International Journal of Educational Technology in Higher Education, 17(9). https://doi.org/10.1186/s41239-020-01786.

Chen, T., Peng, L., Yin, X., Rong, J., Yang, J., \& Cong, G. (2020). Analysis of user satisfaction with online education platforms in China during the COVID-19 pandemic. Healthcare, 8(3), 200. https:// doi.org/10.3390/healthcare 8030200

Cho, M. H., \& Byun, M. (2017). Non-native English-speaking students' lived learning experiences with MOOCs in a regular college classroom. International Review of Research in Open and Distributed Learning: IRRODL, 18(5), 173-190.

Chopra, A., \& Syazwani, A. (2020). Investigating the common factor of drop out based on learner's perspective and dropout rate in MOOCs in Malaysia. International Research Journal of Engineering and Technology (IRJET), 07(03), 5317-5326.

Christensen, G., Steinmetz, A., Alcorn, B., Bennett, A., Woods, D., \& Emanuel, E. J. (2013). The MOOC phenomenon: Who takes massive open online courses and why? http://dx.doi.org/10.2139/ ssrn.2350964

Chugh, R., \& Ruhi, U. (2018). Social media in higher education: A literature review of Facebook. Education and Information Technologies, 23(2), 605-616.

Colas, J. F., Sloep, P. B., \& Garreta-Domingo, M. (2016). The effect of multilingual facilitation on active participation in MOOCs. The International Review of Research in Open and Distributed Learning, 17(4).

Creswell, J.W. (2013). Five qualitative approaches to inquiry. Qualitative inquiry and research design: Choosing among five approaches (pp. 69-110). SAGE Publications.

Dennen, V. P., \& Bong, J. (2018). Crosscultural dialogues in an open online course: Navigating national and organizational cultural differences. TechTrends : Linking Research and Practice to Improve Learning, 62(4), 383 392. https://doi.org/10.1007/s11528-0180276-7

De Waard, I., Gallagher, M. S., ZeleznyGreen, R., Czerniewicz, L., Downes, S., Kukulska-Hulme, A., \& Willems, J. (2014). Challenges for conceptualising EU MOOC for vulnerable learner groups. Proceedings of the European MOOC Stakeholder Summit 2014, 33-42.

Ding, Y., Wang, M., He, Y., Ye, A. Y., Yang, X., Liu, F., ... \& Wei, L. (2014). "Bioinformatics: Introduction and Methods," a bilingual Massive Open Online Course (MOOC) as a new example for global bioinformatics education. PLoS Computational Biology, 10(12), e1003955.

Dorner, D. G., \& Gorman, G. E. (2006). Information literacy education in Asian developing countries: Cultural factors affecting curriculum development and programme delivery. International Federation of Library Associations and Institutions Journal, 32(4), 281-293. https://doi. org/10.1177/0340035206074063 
Gannon-Leary, P., \& Fontainha, E. (2007). Communities of practice and virtual learning communities: Benefits, barriers and success factors. Barriers and Success Factors. eLearning Papers, (5).

Garrison, D. R., Anderson, T., \& Archer, W. (2000). Critical inquiry in a text-based environment: Computer conferencing in higher education. The Internet and Higher Education, 2(2), 87-105.

Gillham, B. (2000). Case study research: underlying principles. Case study research methods. (pp. 1-8). Bloomsbury.

Guokr. (2014, August). 2014 annual report on Chinese learners' MOOC experiences. Retrievedfrom http://mooc.guokr.com/ post/610674/

Hara, N., Bonk, C. J., \& Angeli, C. (2000). Content analysis of online discussion in an applied educational psychology course. Instructional Science, 28(2), 115-152.

Henri, F. (1992). Computer conferencing and content analysis. In A. Kaye (Ed.), Collaborative learning through computer conferencing: The Najaden papers (pp.117-36). Springer-Verlag.

Hofstede, G. (1983). The cultural relativity of organizational practices and theories. Journal of International Business Studies, 75-89.

Hofstede, G. (1986). Cultural differences in teaching and learning. International Journal of Intercultural Relations, 10(3), 301-320.

Hofstede, G. (2007). Asian management in the 21st century. Asia Pacific Journal of Management, 24(4), 411-420.

Hofstede, G., \& Minkov, M. (2010). Longversus short-term orientation: new perspectives. Asia Pacific Business Review,16(4), 493-504.

Hofstede, G. (2011). Dimensionalizing cultures: The Hofstede model in context. Online Readings in Psychology and Culture, 2(1), 8.
Hofstede Insights. (2016). National culture. https://www.hofstede-insights.com/ models/national-culture/

Huett, J., Moller, L., Harvey, D., Holder, D., Godshalk, V., \&Engstrom, M. (2007). Examining the use of learning communities to increase motivation. In R. Luppicini (Ed.), Online learning communities (pp. 189-204). Information Age Publishing.

Hui, A. N., \& Lau, S. (2010). Formulation of policy and strategy in developing creativity education in four Asian Chinese societies: A policy analysis. The Journal of Creative Behavior, 44(4), 215-235.

Husain, K. (1995). Assessing implicit instructions of language learning strategies by ESL teachers. Indian Journal of Applied Linguistics, 21(2), 27-40.

Johnson, N., Bates, T., Donovan, T., \& Seaman, J. (2019). Tracking online education in Canadian universities and colleges: National survey of online and digital learning 2019 national report. Canadian Digital Learning Research Association. https://onlinelearningsurveycanada.ca/wpcontent/uploads/2020/05/2019 national en.pdf

Jones, M. L. (2007). Hofstede - Culturally questionable? Oxford Business \& Economics Conference. Oxford, UK.

Kapoor, K. K., Tamilmani, K., Rana, N. P., Patil, P., Dwivedi, Y. K., \& Nerur, S. (2018). Advances in social media research: Past, present, and future. Information Systems Frontiers, 20(3), 531-558

Kimmerle, J., Moskaliuk, J., Oeberst, A., \& Cress, U. (2015). Learning and collective knowledge construction with social media: A process-oriented perspective. Educational Psychologist, 50(2), 120-137.

Kizilcec, R. F., Saltarelli, A. J., Reich, J., \& Cohen, G. L. (2017). Closing global achievement gaps in MOOCs. Science, 355(6322), 251-252. 
Krasny, M. E., DuBois, B., Adameit, M., Atiogbe, R., Alfakihuddin, M. L. B., Bolderdene, T., ... \& Shian-Yun, L. (2018). Small groups in a social learning MOOC (sIMOOC): Strategies for fostering learning and knowledge creation. Online Learning, 22(2), 119-139.

Ku, H. Y., \& Lohr, L. L. (2003). A case study of Chinese student's attitudes toward their first online learning experience. Educational Technology Research and Development, 51(3), 95-102.

Lambert, S. R. (2020). Do MOOCs contribute to student equity and social inclusion? A systematic review 2014-18. Computers \& Education, 145, 103693. https://doi. org/10.1016/j.compedu.2019.103693

Li, W. (2012). Theory and practice of online learning community's creation and application by means of QQ group software. International Journal of Emerging Technology and Advanced Engineering, 2(10), 42-46.

Li, B., Wang, X., \& Tan, S. C. (2018). What makes MOOC users persist in completing MOOCs? A perspective from network externalities and human factors. Computers in Human Behavior, 85, 385395.

Lin, X.-F., Deng, C., Hu, Q., \& Tsai, C.C. (2019). Chinese undergraduate students' perceptions of mobile learning: conceptions, learning profiles, and approaches. Journal of Computer Assisted Learning, 35(3), 317-333. https://doi. org $/ 10.1111 /$ jcal.12333

Liu, L. (2017). An empirical analysis of Chinese college learners' obstacles to MOOC learning in an English context. English Language Teaching, 10(3), 136150.

Liu, X., Liu, S., Lee, S., \& Magjuka, R. J. (2010). Cultural differences in online learning: International student perceptions. Educational Technology \& Society, 13(3),
177-188.

Lin, J. M. C., Lee, G. C., \& Chen, H. Y. (2004). Exploring potential uses of ICT in Chinese language arts instruction: Eight teachers' perspectives. Computers \& Education, 42(2), 133-148.

Ma, Q. (2017). A multi-case study of university students' language-learning experience mediated by mobile technologies: a sociocultural perspective. Computer Assisted Language Learning, 30(3/4), 183-203

Mackness, J., Mak, S., \& Williams, R. (2010). The ideals and reality of participating in a MOOC. In Proceedings of the 7th International Conference on Networked Learning 2010 (pp. 266-275). University of Lancaster.

Oberg, K. (1960). Culture shock: Adjustmentto new cultural environment. Practical Anthropologist, 7, 177-182.

Oyserman, D., Coon, H. M., \& Kemmelmeier, M. (2002). Rethinking individualism and collectivism: Evaluation of theoretical assumptions and meta-analyses. Psychological Bulletin, 128(1), 3.

Peeters, W. (2019). The peer interaction process on Facebook: A social network analysis of learners' online conversations. Education and Information Technologies, 24(5), 3177-3204.

Phang, C. W., Kankanhalli, A., \& Sabherwal, R. (2009). Usability and sociability in online communities: A comparative study of knowledge seeking and contribution. Journal of the Association for Information Systems, 10(10), 2.

Sadykova, G. (2013). Learning in new online cultures: East meets West. In C. Meskill (Ed.), Online teaching and learning: Sociocultural perspectives (pp. 21-38). Bloomsbury.

Sanchez-Gordon, S., \& Luján-Mora, S. (2014). MOOCs gone wild. In Proceedings of the 8th International Technology, Education and Development Conference (INTED 
2014) (pp. 1449-1458). Valencia, Spain.

Schwier, R. A. (2007). A typology of catalysts, emphases and elements of virtual learning communities. In R. Luppicini (Ed.), Online learning communities (pp. 17-39). Information Age Publishing.

Siemens, G. (2013). Massive open online courses: Innovation in education? In R. McGreal, et al. (Eds). Open educational resources: Innovation, research and practice (pp. 5-15). Athabasca University Press.

Sobaih, A. E. E., Moustafa, M. A., Ghandforoush, P., \& Khan, M. (2016). To use or not to use? Social media in higher education in developing countries. Computers in Human Behavior, 58, 296305.

Stork, M. G., Zhang, J., \& Wang, C. X. (2018). Building multicultural awareness in university students using synchronous technology. TechTrends: Linking Research and Practice to Improve Learning, 62(1), 11-14. https://doi.org/10.1007/s11528017-0235-8

Swan, K., \& Shea, P. (2005). The development of virtual learning communities. In S. R. Hiltz \& R. Goldman (Eds.), Learning together online: Research on asynchronous learning networks (pp. 239260). Routledge.

Tahirsylaj, A., Mann, B., \& Matson, J. (2018). Teaching creativity at scale: Overcoming language barriers in a MOOC. International Journal of Innovation, Creativity and Change, 4(2), 1-19.

Tang, H. (in press). Person-centered analysis of self-regulated learner profiles in MOOCs: A cultural perspective. Educational Technology Research and Development. https://doi.org/10.1007/ s11423-021-09939-w

Tang, H., \& Carr-Chellman, A. (2016). Massive open online courses and educational equality in China: A qualitative inquiry. Journal of Educational Technology Development \& Exchange, 9(1). http://aquila.usm.edu/jetde/vol9/ iss $1 / 4$

Tang, H., \& Wang, N. (2017). Have massive open online courses disrupted higher education around the globe? Exploring the cultural perspective. International Journal of Technology in Teaching and Learning, 13(1), 45-54.

Tang, H., \& Wang, S. (2019, October). Revisiting the myth of disruptive innovation: An exploratory study of Chinese Learners' Perception of Massive Open Online Courses. In 2019 Eighth International Conference on Educational Innovation through Technology (EITT) (pp. 71-77). IEEE.

Tang, H., Xing, W., \& Pei, B. (2018). Exploring the temporal dimension of forum participation in MOOCs. Distance Education, 39(3), 353-372.

Tellis, W. (1997a). Introduction to case study. The qualitative report, 269. Urban Land Institute.

Tellis, W. (1997b). Application of a case study methodology. The qualitative report, 3(3), 1-19. http://nsuworks.nova.edu/tqr/vol3/ iss $3 / 1$

Thompson, L., \& Ku, H. Y. (2005). Chinese graduate students' experiences and attitudes toward online learning. Educational Media International, 42(1), 33-47.

Wang, V., \& Farmer, L. (2008). Adult Teaching Methods in China and Bloom's Taxonomy. International Journal for the Scholarship of Teaching and Learning, 2(2), n2.

Welsh, D. H., \& Dragusin, M. (2013). The new generation of massive open online courses (MOOCS) and entrepreneurship education. Small Business Institute Journal, 9(1), 51.

Wenger, E. C., \& Snyder, W. M. (2000). 
Communities of practice: The organizational frontier. Harvard Business Review, 78(1), 139-146.

Wu, J. J., \& Albanese, D. (2010). Asian creativity, chapter one: Creativity across three Chinese societies. Thinking Skills and Creativity, 5(3), 150-154.

Xing, W., Tang, H., \& Pei, B. (2019). Beyond positive and negative emotions: Looking into the role of achievement emotions in discussion forums of MOOCs. The Internet and Higher Education, 43, 100690.

Yang, J. C., Quadir, B., Chen, N. S., \& Miao, Q. (2016). Effects of online presence on learning performance in a blog-based online course. The Internet and Higher Education, 30, 11-20.

Zeng, F., Deng, G., Wang, Z., \& Liu, L. (2016). WeChat: A new clinical teaching tool for problem-based learning. International Journal of Medical Education, 7, 119-121.

Zhang, Q., Peck, K. L., Hristova, A., Jablokow, K. W., Hoffman, V., Park, E., \& Bayeck, R. Y. (2016). Exploring the communication preferences of MOOC learners and the value of preference-based groups: Is grouping enough? Educational Technology Research and Development, 64(4), 809-837.

Zhao, N., \& McDougall, D. (2008). Cultural influences on Chinese students, asynchronous online learning in a Canadian university. International Journal of E-Learning \& Distance Education, 22(2).

Zhang, Z., \& Xue, Y. (2015). An investigation of how Chinese university students use social software for learning purposes. Procedia-Social and Behavioral Sciences, 186, 70-78.

Zhu, X., \& Liu, J. (2020). Education in and after Covid-19: Immediate responses and long-term visions. Postdigital Science and Education, 2(3), 695-699.

\section{Contact the Author:}

Qing Zhang

qing.zhang@oswego.edu

State University of New York at Oswego

Hengtao Tang

htang@mailbox.sc.edu

University of South Carolina

Barbara B. Lockee

lockeebb@vt.edu

Virginia Polytechnic Institute and State

University

Kathryn Jablokow

KWL3@psu.edu

The Pennsylvania State University 